\title{
Comparison of Safety and Efficacy of Different Class of Anti-hypertensive Drugs Prescribed in Patients with Hypertension
}

\author{
Jalpa Suthar $^{1 *}$, Amishi Pathak ${ }^{2}$, Bhavik Shelat ${ }^{3}$ \\ ${ }^{1}$ Assistant Professor, Department of Pharmacology, Ramanbhai Patel College of Pharmacy, CHARUSAT, Changa, Gujarat, INDIA. \\ ${ }^{2}$ M.Pharm. (Clinical Pharmacy), Ramanbhai Patel College of Pharmacy, CHARUSAT, Changa, Gujarat, INDIA. \\ ${ }^{3}$ Director, Sheth H. J. Mahagujarat Hospital, Nadiad, Gujarat, INDIA.
}

\begin{abstract}
Background: Hypertension is considered as key indicator for various cardiovascular diseases. Blood pressure is the pressure of blood on arterial walls. The use of antihypertensive drugs is increased worldwide. Hypertension treatment strategy varies widely in terms of initial drug of choice from diuretic to ACEls/ARBs/ CCBs and from monotherapy to combination therapy. Objectives: To compare the safety and efficacy of different class of Antihypertensive drugs prescribed in patients with hypertension. Methods: A Prospective observational and longitudinal study which included 150 newly diagnosed hypertensive patients attending medical outpatient department of Sheth HJ Mahagujarat Hospital, Nadiad. Demographic details and baseline blood pressure of the patients were recorded. Patients were followed up after 15 days and one-month period of treatment. Adverse effects were noted at the time of treatment. Results: The mean age of patients 55 years in which both genders were equally exposed. Diabetes Mellitus was major associated condition and patients above 50 years were at high risk for hypertension. Patients receiving ARBs showed significant control in blood pressure $(p=0.03)$ as monotherapy when compared with other Anti-hypertensive drugs. In FDCs, Losartan + Hydrochlorothiazide $(p=0.03,0.005)$, Telmisartan + Metoprolol Succinate $(p=0.00002,0.005)$ and Losartan + Amlodipine $(p=0.03,0.0003)$ proved significance. Reported adverse effects were recorded at the time of treatment as safety parameter. Conclusion: Hypertension was most common in patients above 50 years. ARBs were most prescribed as monotherapy. In FDCs most suitable combinations were with ARBs with few adverse effects.
\end{abstract}

Key words: Hypertension, Safety, Efficacy, ARBs, FDCs.

\section{INTRODUCTION}

Hypertension is epidemic affecting one billion people and common risk factor of death throughout the world. The prevalence rate of hypertension is increasing rapidly in India, varying from 4 to $15 \%$ in urban and 2 to $8 \%$ in rural population. Hypertension is divided into two parts that is Systolic pressure (contraction pump out) and Diastolic pressure (relaxation time period between beats). Normal blood pressure of the person is $120 / 80 \mathrm{mmHg}$ and the person whose reading is above $140 / 90 \mathrm{mmHg}$ is considered as hypertensive. ${ }^{1}$

Normally a patient having high blood pressure does not show any symptom until he develops the condition of Stroke, Coronary artery disease, Cardiomyopathy or Renal damage. Due to these, many a times condition of hypertension remains undiagnosed till the complications develops. ${ }^{2}$ The symptoms of hypertension are frequent headache, chest heaviness, dizziness, vertigo, easily fatigue and many more. There are many risk factors for high blood pressure such as Overweight, Age, Family history, excess alcohol intake, unhealthy diet, less physical activity, stress and many more. ${ }^{3}$

There is consistent increase in use of antihypertensive drugs worldwide. For the treatment of hypertension, the compliance rates are good with monotherapy, average with two separate drugs, poor when more than two pills are used and hence, they are switched over from monotherapy to single
DOI: 10.5530/ijopp.12.4.54

Address for correspondence: Dr. Jalpa Suthar Assistant Professor, Department of Pharmacology, Ramanbhai Patel College of Pharmacy (RPCP), Charotar University of Science and Technology (CHARUSAT), At \& Post- Changa, Tal- Petlad, Anand, Gujarat-388 421. INDIA. Phone no: +919825907538 E-Mail: jalpasuthar.ph@charusat. ac.in

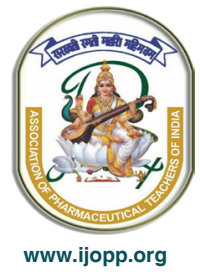


pill FDC. Hypertension treatment strategies varies widely over time in terms of initial drug of choice from diuretic to ACEI/ ARB/ CCB from monotherapy to low dose combination single pill therapy. ${ }^{4}$

According to the Eighth Joint National Committee (JNC 8), first line therapy for hypertension in the general population should include Thiazide Diuretics (TDs), Calcium Channel Blockers (CCBs), Angiotensin Converting Enzyme Inhibitors (ACEIs), or Angiotensin Receptor Blockers (ARBs) monotherapy. If targeted BP is not reached within one month after initiating therapy, the dosage of medication should be increased or second medication is added. ${ }^{5}$ In this study, we compared efficacy and safety of different class of Anti-hypertensive drugs prescribed in patients with hypertension. In addition, study also look into the aspect of the drug utilization patterns of antihypertensive drugs.

\section{MATERIALS AND METHODS}

Study Design: A Prospective observational and longitudinal study.

Study Site: Sheth HJ Mahagujarat Hospital, Nadiad, Gujarat- India.

Study Period: Study was carried for 6 months duration from June to December 2018, after approval from Ethics of Ramanbhai Patel College of Pharmacy, CHARUSAT- Changa, India Protocol Number: RPCP/ IECHR/1/2018-2019/PG/R-04.01.

Sample Size: 150 newly diagnosed hypertensive patients attending to Medical Outpatient Department were collected in Case Record Form.

Patient Inclusion Criteria: Newly diagnosed hypertensive patients attending to medical OPD of the hospital were included. Hypertensive patients who received different Anti-hypertensive drugs were divided into different groups.

Study Procedure: Parameter of efficacy and safety were evaluated by personal interaction with patient and recorded in Case Record Form. Efficacy parameter included change in systolic and diastolic blood pressure in patients receiving different Anti-hypertensive treatment. Safety profile was evaluated by adverse drug reactions observed in patients. First follow up was taken after 15 days and second follow up after one month of patient's treatment. Those patients who were receiving different Anti-hypertensive drugs were interviewed personally after taking their written consent as the procedure is shown in Figure 1.
Statistical Analysis: Descriptive Statistics was used to generate results. Data was analyzed by Microsoft Excel 2007 using Paired $t$-test. The $p$ value $(<0.05)$ was considered statistically significant.

\section{RESULTS}

Total 150 patients were included in study in which there were $77(51 \%)$ males and $73(49 \%)$ females attending to outpatient department of the hospital. Both genders were equally exposed to hypertension with the mean age of patients was 55 years. Diabetes Mellitus-II was major associated condition $(21 \%)$ along with hypertension as shown in Figure 2.

Elder agewas considered as a risk for the cardiovascular disease. In present study, $84.66 \%$ of patients were

Patients newly diagnosed with hypertension were enrolled $(n=150)$

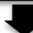

Different anti-hypertensive drugs were prescribed by physician according to the condtion of the patient

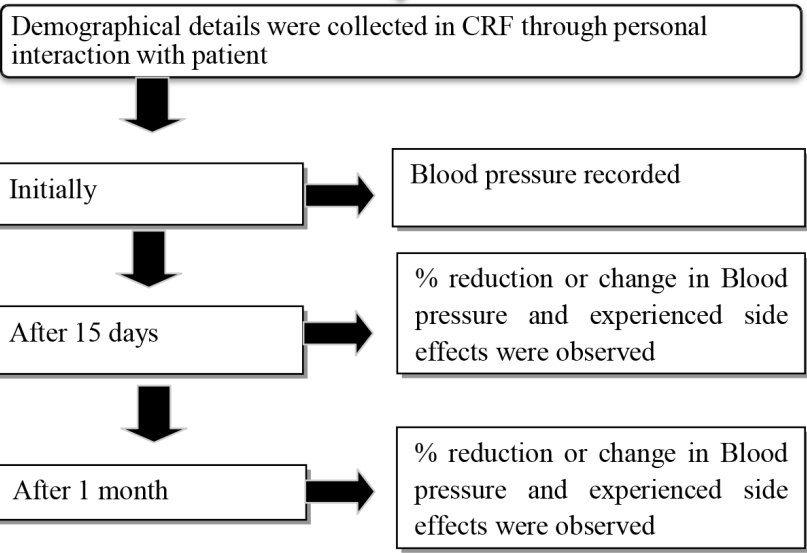

Figure 1: Patient Recruitment Process.

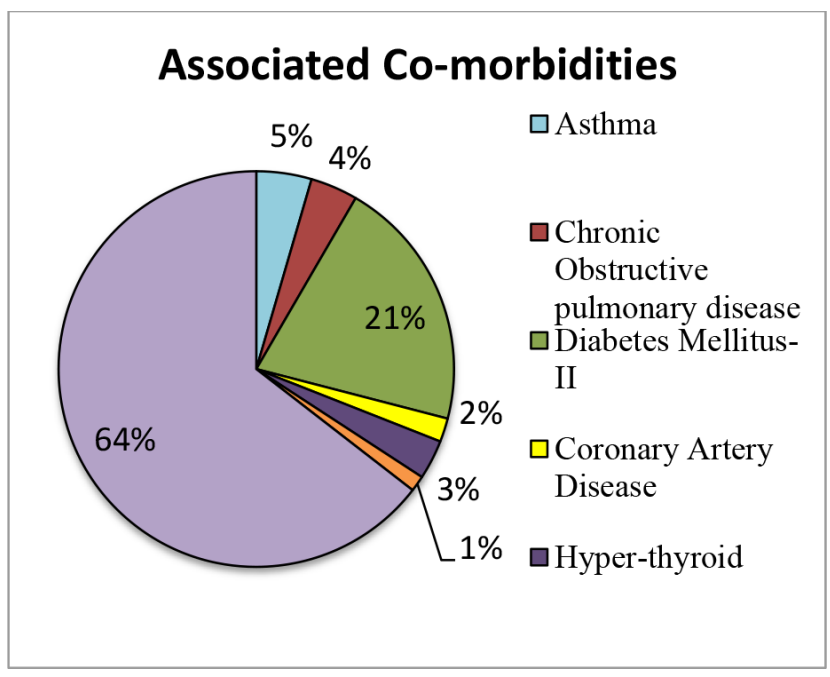

Figure 2: Associated Co-morbidities. 
above 50 years of age, which showed direct relationship with hypertension. On the other side obesity was also identified as one of the risks factors in hypertensive patients while the history of Smoking was also observed in few patients. Female patients $(20.54 \%)$ were observed with history of menopause, in addition to other risk factors as shown in Table 1.

Patients were segregated in different groups as per the drug treatment given by physician to treat hypertension. Patient's initial blood pressure was recorded. After 15

\section{Table 1: Risk Factors in patients with hypertension.}

\begin{tabular}{ccccc}
$\begin{array}{c}\text { Sr } \\
\text { No: }\end{array}$ & Factors & $\begin{array}{c}\text { Male } \\
(\boldsymbol{n}=77)\end{array}$ & $\begin{array}{c}\text { Female } \\
(\boldsymbol{n}=73)\end{array}$ & $\begin{array}{c}\text { Total } \\
\text { number } \\
(\boldsymbol{n}, \%)\end{array}$ \\
\hline \multirow{2}{*}{ Age } & Below 50 years & 15 & 8 & $23(15.33 \%)$ \\
& Above 50 years & 62 & 65 & $127(84.66 \%)$ \\
2 & Obesity & 17 & 27 & $44(29.33 \%)$ \\
3 & Smoking & 41 & - & $41(27.33 \%)$ \\
4 & Family History & 20 & 18 & $38(25.33 \%)$ \\
5 & Hyperlipidemia & 13 & 11 & $24(16 \%)$ \\
6 & Menopause & - & 15 & $15(20.54 \%)^{*}$ \\
7 & Tobacco addiction & 02 & - & $02(1.33 \%)$ \\
\hline
\end{tabular}

*Menopause, $n=73$ is considered as 100 percentage. day and one-month treatment period blood pressure control was also recorded in all groups of patients. Patients experience to any symptoms or abnormalities was recorded as side effects as indicated in Table 2.

In Monotherapy, Angiotensin Receptor Blockers were mostly prescribed (17\%) to patients as it gives controlled systolic as well as diastolic pressure followed by ACE Inhibitors, Calcium Channel Blockers, Beta Blockers and Diuretics. There were some common side effects to the patients taking these drugs. Angiotensin Receptor Blockers showed significant reduction in blood pressure as compared to other class of drugs using Paired $t$-test.

In present study, $92(61 \%)$ patients were prescribed with different types of Fixed Dose Combinations such as Losartan + Hydrochlorothiazide (2\%), Amlodipine + Atenolol (3\%), Telmisartan + Amlodipine (26\%), Telmisartan + Chlorthalidone (19\%), Telmisartan + Metoprolol Succinate (9\%), Telmisartan + Hydrochlorothiazide (1\%), Losartan + Amlodipine (2\%) as indicated in Table 3.

In Fixed Dose Combinations (FDCs) therapy, initial average systolic blood pressure was $170 \pm 14.35 \mathrm{mmHg}$ and diastolic blood pressure $100 \pm 8.42 \mathrm{mmHg}$ was reported. After receiving FDCs, average systolic blood

\section{Table 2: Efficacy and Safety data of different class of Anti-hypertensive drugs ( $n=58$ ).}

\begin{tabular}{|c|c|c|c|c|c|}
\hline \multirow{2}{*}{$\begin{array}{c}\text { Class of Anti- } \\
\text { hypertensive drugs } \\
\text { ( } n=\text { no of patients) }\end{array}$} & \multicolumn{3}{|c|}{ Blood Pressure $(\mathrm{mmHg})$} & \multirow[b]{2}{*}{ Side effects } & \multirow[b]{2}{*}{$P$ Value } \\
\hline & Initial & $\begin{array}{c}2^{\text {nd }} \text { visit } \\
\text { (After } 15 \text { days) }\end{array}$ & $\begin{array}{c}3^{\text {rd }} \text { visit } \\
\text { (After } 1 \text { month) }\end{array}$ & & \\
\hline $\begin{array}{c}\text { Calcium Channel } \\
\text { Blockers } \\
(n=10)\end{array}$ & $\begin{array}{c}160 / 90 \\
\text { SP-160 } \pm 5.77 \\
\text { DP-90 } \pm 0\end{array}$ & $\begin{array}{c}140 / 90 \\
\text { SP-140 } \pm 5.77 \\
\text { DP-90 } \pm 5.77\end{array}$ & $\begin{array}{c}140 / 80 \\
\text { SP-140 } \pm 15.27 \\
\text { DP- } 80 \pm 5.77\end{array}$ & $\begin{array}{l}\text { Dizziness } \\
\text { Fatigue } \\
\text { Constipation } \\
\text { Nausea } \\
\text { Hyper Acidity }\end{array}$ & $\begin{array}{l}(S)=0.07 \\
(D)=0.18\end{array}$ \\
\hline $\begin{array}{l}\text { Beta Blockers } \\
\qquad(n=9)\end{array}$ & $\begin{array}{c}170 / 90 \\
\text { SP-170 } \pm 11.40 \\
\text { DP-90 } \pm 5.47\end{array}$ & $\begin{array}{c}150 / 90 \\
\text { SP-150 } \pm 8.36 \\
\text { DP-90 } \pm 4.47\end{array}$ & $\begin{array}{c}140 / 90 \\
\text { SP-140 } \pm 5.47 \\
D P-90 \pm 4.47\end{array}$ & $\begin{array}{c}\text { Fatigue } \\
\text { Dizziness } \\
\text { Muscle Cramps } \\
\text { Headache } \\
\text { Insomnia } \\
\text { Nausea } \\
\text { Constipation }\end{array}$ & $\begin{array}{l}(S)=0.005 \\
(D)=0.37\end{array}$ \\
\hline $\begin{array}{l}\text { ACE Inhibitors } \\
\quad(n=13)\end{array}$ & $\begin{array}{c}170 / 100 \\
\text { SP-170 } \pm 7.07 \\
\text { DP-100 } \pm 14.14\end{array}$ & $\begin{array}{c}150 / 80 \\
\text { SP-150 } \pm 7.07 \\
\text { DP- } 80 \pm 0\end{array}$ & $\begin{array}{c}130 / 90 \\
\text { SP- } 130 \pm 0 \\
\text { DP-90 } \pm 7.07\end{array}$ & $\begin{array}{l}\text { Dry Cough } \\
\text { Fatigue } \\
\text { Dizziness } \\
\text { Nausea }\end{array}$ & $\begin{array}{l}(S)=0.09 \\
(D)=0.20\end{array}$ \\
\hline $\begin{array}{l}\text { Angiotensin } \\
\text { Receptor Blockers } \\
(n=25)\end{array}$ & $\begin{array}{c}160 / 90 \\
\text { SP-160 } \pm 10 \\
D P-90 \pm 0\end{array}$ & $\begin{array}{c}140 / 80 \\
\text { SP-140 } \pm 11.54 \\
\text { DP- } 80 \pm 0\end{array}$ & $\begin{array}{c}130 / 80 \\
\text { SP- } 130 \pm 0 \\
\text { DP- } 80 \pm 5.77\end{array}$ & $\begin{array}{l}\text { Headache } \\
\text { Fatigue } \\
\text { Nausea } \\
\text { Dizziness }\end{array}$ & $\begin{array}{l}(S)=0.03 \\
(D)=0.03\end{array}$ \\
\hline $\begin{array}{l}\text { Diuretics } \\
\quad(n=1)\end{array}$ & $170 / 90$ & $150 / 80$ & $140 / 80$ & $\begin{array}{l}\text { Headache } \\
\text { Fatigue } \\
\text { Dizziness } \\
\uparrow \text { Thirst }\end{array}$ & - \\
\hline
\end{tabular}

* $P$ value $<0.05$ was considered significant using paired $t$-test.

* $\mathrm{SP}=$ systolic pressure and $\mathrm{DP}=$ diastolic pressure. 
Table 3: Comparison of FDCs with reference to Safety and Efficacy ( $n=92)$.

\begin{tabular}{|c|c|c|c|c|c|}
\hline \multirow[b]{2}{*}{$\begin{array}{l}\text { Class of Anti-hypertensive drug } \\
\text { ( } n=\text { no. of patients) }\end{array}$} & \multicolumn{3}{|c|}{ Blood Pressure (mmHg) } & \multirow{2}{*}{$\begin{array}{l}\% \text { reduction } \\
\text { in } \mathrm{BP}\end{array}$} & \multirow[b]{2}{*}{$P$ Value } \\
\hline & Initial & $\begin{array}{c}2^{\text {nd }} \text { visit } \\
\text { (After } 15 \text { days) }\end{array}$ & $\begin{array}{c}3^{\text {rd }} \text { visit } \\
\text { (After } 1 \text { month) }\end{array}$ & & \\
\hline $\begin{array}{l}\text { Losartan + Hydrochlorothiazide } \\
\left(\begin{array}{c}50+12.5 \mathrm{mg}) \\
(n=3)\end{array}\right.\end{array}$ & $\begin{array}{c}170 / 90 \\
\text { SP- } 170 \pm 5.77 \\
\text { DP- } 90 \pm 5.77\end{array}$ & $\begin{array}{l}150 / 80 \\
\text { SP-150 } \pm 5.77 \\
\text { DP- } 80 \pm 0\end{array}$ & $\begin{array}{c}140 / 80 \\
\text { SP-140 } \pm 5.77 \\
\text { DP- } 80 \pm 5.77\end{array}$ & $30 \%$ & $\begin{array}{l}(S)=0.03 \\
(D)=0.005\end{array}$ \\
\hline $\begin{array}{l}\text { Amlodipine }+ \text { Atenolol } \\
\qquad(50+5 \mathrm{mg}) \\
(n=4)\end{array}$ & $\begin{array}{c}160 / 70 \\
\text { SP-160 } \pm 10 \\
\text { DP-70 } \pm 12.90\end{array}$ & $\begin{array}{c}150 / 70 \\
\mathrm{SP}-150 \pm 5.77 \\
\mathrm{DP}-70 \pm 8.16\end{array}$ & $\begin{array}{c}130 / 80 \\
\text { SP-130 } \pm 5 \\
\text { DP- } 80 \pm 0\end{array}$ & $30 \%$ & $\begin{array}{c}(S)=0.004 \\
(D)=0.49\end{array}$ \\
\hline $\begin{array}{c}\text { Telmisartan }+ \text { Amlodipine } \\
\left(\begin{array}{c}(40+5 \mathrm{mg}) \\
(n=39)\end{array}\right.\end{array}$ & $\begin{array}{c}170 / 100 \\
\text { SP-170 } \pm 14.35 \\
\text { DP-100 } \pm 8.42\end{array}$ & $\begin{array}{c}150 / 90 \\
\text { SP-150 } \pm 8.23 \\
\text { DP- } 90 \pm 5.43\end{array}$ & $\begin{array}{c}140 / 80 \\
\text { SP-140 } \pm 6.94 \\
\text { DP- } 80 \pm 5.10\end{array}$ & $30 \%$ & $\begin{array}{l}(S)=5.23 \\
(D)=8.29\end{array}$ \\
\hline $\begin{array}{c}\text { Telmisartan }+ \text { Chlorthalidone } \\
\left(\begin{array}{c}(40+12.5 \mathrm{mg}) \\
(n=29)\end{array}\right.\end{array}$ & $\begin{array}{c}170 / 90 \\
\text { SP-170 } \pm 12.41 \\
\text { DP-90 } \pm 9.25\end{array}$ & $\begin{array}{c}140 / 80 \\
\text { SP-140 } \pm 9.66 \\
\text { DP-80 } \pm 5.39\end{array}$ & $\begin{array}{c}140 / 80 \\
\text { SP-140 } \pm 10.21 \\
\text { DP- } 80 \pm 6.75\end{array}$ & $30 \%$ & $\begin{array}{l}(S)=1.11 \\
(D)=2.86\end{array}$ \\
\hline $\begin{array}{l}\text { Telmisartan }+ \text { Metoprolol Succinate } \\
\qquad \begin{array}{c}(40+25 \mathrm{mg}) \\
(n=13)\end{array}\end{array}$ & $\begin{aligned} & 160 / 90 \\
& \text { SP-160 } \pm 15.81 \\
& \text { DP-90 } \pm 9.12\end{aligned}$ & $\begin{array}{c}140 / 90 \\
\text { SP-140 } \pm 7.59 \\
\text { DP- } 90 \pm 5.99\end{array}$ & $\begin{array}{c}130 / 80 \\
\text { SP-130 } \pm 6.40 \\
\text { DP- } 80 \pm 5.54\end{array}$ & $30 \%$ & $\begin{array}{l}(S)=0.00002 \\
(D)=0.005\end{array}$ \\
\hline $\begin{array}{c}\text { Telmisartan }+ \text { Hydrochlorothiazide } \\
(40+12.5 \mathrm{mg}) \\
(n=1)\end{array}$ & $180 / 80$ & $140 / 80$ & $130 / 80$ & $50 \%$ & - \\
\hline $\begin{array}{l}\text { Losartan }+ \text { Amlodipine } \\
\qquad \begin{array}{c}(50+5 \mathrm{mg}) \\
(n=3)\end{array}\end{array}$ & $\begin{array}{l}\mathrm{SP}-170 \pm 5.77 \\
\mathrm{DP}-100 \pm 5.77\end{array}$ & $\begin{array}{c}\mathrm{SP}-150 \pm 5.77 \\
\mathrm{DP}-80 \pm 0\end{array}$ & $\begin{array}{c}140 / 70 \\
\text { SP-140 } \pm 5.77 \\
\text { DP-70 } \pm 5.77\end{array}$ & $30 \%$ & $\begin{array}{c}(S)=0.03 \\
(D)=0.0003\end{array}$ \\
\hline
\end{tabular}

* $P$ value $<0.05$ was considered significant using paired $t$-test.

* $\mathrm{SP}=$ systolic pressure and $\mathrm{DP}=$ diastolic pressure.

pressure was controlled up to $140 \pm 6.94 \mathrm{mmHg}$ and diastolic blood pressure was controlled up to $80 \pm 5.10$ mmHg. Overall FDCs showed average 30\% reduction in blood pressure. Among all FDCs, few like Losartan + Hydrochlorothiazide $(p=0.03,0.005)$, Telmisartan + Metoprolol Succinate $(p=0.00002,0.005)$ and Losartan + Amlodipine $(p=0.03,0.0003)$ showed statistical significance.

\section{DISCUSSION}

In the present study, total 150 newly diagnosed hypertensive patients were enrolled. Anti-hypertensive drugs of different classes were prescribed by physician according to patient's suitability. In our study the mean age of patients was 55 years, including both males and females. Similarly, study by Machado et al. reported the mean age of 55 years in which both genders were equally distributed. ${ }^{6}$ The present study reveals that, high risk of hypertension was seen in patients above 50 years of age as well as relation with risk factors such as obesity, family history along with hyperlipidemia. Smoking was considered major risk factor in men while menopause was common observed in women. Likewise, in study by
Singh $\mathrm{S}$ et al. concluded that increasing age is one of the independent risk factor. Men are at more risk of being hypertensive than females due to factors like tobacco chewing, smoking and less physical activities.

In present study, majority of patients [13] males and [19] females were suffering from Diabetes Mellitus along with hypertension. Likewise, Gress TW et al. study found that the subjects who are already taking diabetic medications are more likely to have high blood pressure than those without any co-morbidities present. ${ }^{8}$ In present study, all patients were classified as per Joint National Committee (JNC) 8 guidelines for systolic hypertension, as a result 37 patients were in stage I hypertension with systolic blood pressure remains more than 140 to $159 \mathrm{mmHg}$ and 112 patients were in stage II hypertension with blood pressure observed more than $160 \mathrm{mmHg}$.

Only 1 patient in present study was prescribed with loop diuretic (furosemide). Initial blood pressure of patient was $170 / 90 \mathrm{mmHg}$ and after receiving drug therapy 140/80 $\mathrm{mmHg}$ blood pressure was reported. The reported minor side effects after drug therapy were dizziness, headache, increase in thirst and fatigue. 
Diuretics are mostly prescribed to elderly patients as it indicates stroke prevention. ${ }^{9}$

In present study, $10(7 \%)$ patients were prescribed with different Calcium Channel Blockers like clinidipine $(1.33 \%)$, amlodipine $(4.66 \%)$ for blood pressure control. Initial average systolic blood pressure was $160 \pm 5.77$ $\mathrm{mmHg}$ and diastolic blood pressure $90 \pm 0 \mathrm{mmHg}$ was reported and after drug therapy average systolic blood pressure was $140 \pm 15.27 \mathrm{mmHg}$ and diastolic blood pressure was $80 \pm 5.77 \mathrm{mmHg}$. It showed $20 \%$ reduction in blood pressure with minor side effects like constipation, nausea, dizziness, fatigue and hyper acidity. It represented clinical improvement, but no statistical significance observed $(p=0.07)$. In our study, CCBs were prescribed to patients with age above 50 years and as per British Hypertension Society Guidelines CCBs are indicated in elderly patients with isolated systolic hypertension. ${ }^{6}$ One of the study by Chen $\mathrm{N}$ et al. evaluated that CCBs are used as first line therapy in patients who are unable to tolerate Beta Blockers as it reduces cardiovascular events like stroke and myocardial infarction but less effective than ACEIs or ARBs with fewer side effects. ${ }^{10}$

Total $9(6 \%)$ patients were prescribed different Beta Blockers, such like atenolol $(0.66 \%)$, propranolol $(0.66 \%)$ and metoprolol succinate $(4.66 \%)$ for control of blood pressure. The average initial systolic blood pressure was $170 \pm 11.40 \mathrm{mmHg}$ and diastolic blood pressure $90 \pm 5.47 \mathrm{mmHg}$ was reported and after receiving drug therapy average change in systolic blood pressure was $140 \pm 5.47 \mathrm{mmHg}$ and diastolic blood pressure was $90 \pm 4.47 \mathrm{mmHg}$ was observed. Average $30 \%$ reduction in systolic blood pressure with no change in diastolic blood pressure was observed. It represents clinical and statistical significance in controlling systolic blood pressure $(p=0.005)$. Side effects like constipation, nausea, dizziness, fatigue, headache, insomnia and muscle cramps were reported after the drug therapy. Beta Blockers are generally not prescribed in patients associated with conditions like Asthma, COPD, Heart failure, Dyslipidemia or Peripheral vascular disease. ${ }^{6}$

Angiotensin Converting Enzyme Inhibitors like ramipril $(8 \%)$, enalapril (1\%) were prescribed to $13(9 \%)$ patients for blood pressure control. The average initial systolic blood pressure was $170 \pm 7.07 \mathrm{mmHg}$ and diastolic blood pressure $100 \pm 14.14 \mathrm{mmHg}$ was reported. After drug therapy average systolic blood pressure was $130 \pm 0 \mathrm{mmHg}$ and diastolic blood pressure was $90 \pm 7.07$ $\mathrm{mmHg}$ was observed. It showed $40 \%$ reduction in systolic blood pressure with clinical significance, but statistical significance $(p=0.09)$ was not proved in controlling blood pressure. The minor side effects reported after drug therapy were fatigue, dizziness, nausea but the major drawback of this class is patients often complain for dry cough. In our study, patients receiving ACEIs were having associated condition Diabetes Mellitus and according to British Hypertension Society Guidelines, ACEIs are mostly recommended in diabetic nephropathy and heart failure patients. ${ }^{6}$ Likewise AL Drabah et al. highlighted that majority of subjects in their study prescribed with monotherapy ACE Inhibitors because it not only lowers blood pressure but also possesses unique cardio protective property and due to these it reduces death rate, myocardial infarction, stroke and cardiac arrest. ${ }^{11}$

Different Angiotensin Receptor Blockers like telmisartan (13\%), losartan (4\%) were prescribed to $25(17 \%)$ patients in present study. Average initial systolic blood pressure was $160 \pm 10 \mathrm{mmHg}$ and diastolic blood pressure $90 \pm 0 \mathrm{mmHg}$ was reported. After drug treatment average systolic blood pressure was $130 \pm 0 \mathrm{mmHg}$ and diastolic blood pressure was $80 \pm 5.77 \mathrm{mmHg}$. There was $30 \%$ reduction in systolic blood pressure with clinical and statistical significance $(p=0.03)$. Few side effects like headache, dizziness, fatigue and nausea were reported after treatment. ARBs are considered as good option for those patients who are not able to take ACEIs. ${ }^{6}$ Similarly a study by Israili $\mathrm{ZH}$ et al. reported that $\mathrm{ARBs}$ are relatively safe, efficacious and superior Anti-hypertensive drug recommended for blood pressure control. ARBs have unique renoprotective property and are first line Antihypertensive agents in patients with impaired fasting glucose. ${ }^{12}$

In present study, $92(61 \%)$ patients were prescribed with different Fixed Dose Combinations such as Losartan + Hydrochlorothiazide (2\%), Amlodipine + Atenolol (3\%), Telmisartan + Amlodipine (26\%), Telmisartan + Chlorthalidone (19\%), Telmisartan + Metoprolol Succinate $(9 \%)$, Telmisartan + Hydrochlorothiazide (1\%) and Losartan + Amlodipine (2\%). Altogether, FDCs initial average systolic blood pressure was $170 \pm 14.35$ $\mathrm{mmHg}$ and diastolic blood pressure $100 \pm 8.42 \mathrm{mmHg}$ was reported. After drug treatment average systolic blood pressure was controlled to $140 \pm 6.94 \mathrm{mmHg}$ and diastolic blood pressure was controlled to $80 \pm 5.10$ mmHg. Overall FDCs showed average 30\% reduction in blood pressure and Fixed Dose combinations like Losartan + Hydrochlorothiazide, Telmisartan + Metoprolol Succinate and Losartan + Amlodipine proved statistical significance $(p=0.03,0.00002$ and 0.03$)$. Few side effects after drug therapy were dizziness, fatigue, nausea and headache, constipation, hyperacidity, dry cough and muscle cramps. Similarly, a study by Verma AA et al. suggests that FDC formulations are associated with better medication adherence and clinical outcomes. Using 
Fixed Dose Combinations moderately than multiple pill treatment reveals a simple and potentially low-cost intervention that reduces the global burden of mortality and morbidity related to hypertension. Individuals in the Fixed Dose Combinations group frequently receive ARBs with chlorthalidone and hydrochlorothiazide..$^{13}$

The strengths of the study includes, firstly all prescribed drugs showed efficacy and safety to patients while, fixed drug combinations showed good result in newly diagnosed hypertensive patients. Secondly, the efficacy and safety profile of all antihypertensive agents were well reported and showed at par outcome. This was observed in clinical setup through the study. Moreover, the study, examined similar type of finding in clinical set up. The study provided insight on clinical practice of antihypertensive as indicated in guidelines and finding are consistent with reported data.

Despite of all the efforts, there were some drawbacks of the study like small sample size and short duration (6 months) due to this satisfactory sample size was not generated. Patients were not coming for regular follow ups. Therefore, few patients were contacted telephonically and heavy flow of OPD patients limits the pharmacist and patient's interaction.

\section{CONCLUSION}

A study concluded that hypertension was most common among patients $(84.66 \%)$ having age more than 50 years irrespective of genders. Diabetes Mellitus was the major associated condition in patients (21\%) with hypertension. ARBs were considered superior and more often prescribed as it showed better control in blood pressure $(130 / 90 \mathrm{mmHg})$ with minor side effects as monotherapy when compared to other class of drugs. It also showed statistical significance $(p=0.03)$ in blood pressure control. Fixed Dose Combinations were formulations of choice that showed effective control in blood pressure with statistical significance. In our study we found most suitable FDCs were in combination with Angiotensin Receptor Blockers like Losartan + Hydrochlorothiazide $(p=0.03,0.005)$, Telmisartan + Metoprolol Succinate $(p=0.00002,0.005)$ and Losartan + Amlodipine $(p=0.03,0.0003)$ with few adverse effects.

\section{ACKNOWLEDGEMENT}

We would like to thank all the participants for participating in the study and giving their valuable time.

\section{CONFLICT OF INTEREST}

The authors declare no conflict of interest.

\section{ABBREVIATIONS}

ACEIs: Angiotensin Converting Enzyme Inhibitors; ARB's: Angiotensin Receptor Blockers; CCBs: Calcium Channel Blockers; BBs: Beta Blockers; TDs: Thiazide Diuretics; FDCs: Fixed Dose Combinations; JNC: Joint National Committee; CRF: Case Record Form; SP: Systolic Pressure; DP: Diastolic Pressure.

\section{SUMMARY}

A study was conducted with a sample size of 150 patients, which were newly diagnosed with hypertension. It was found that both genders were equally exposed to hypertension and diabetes mellitus was major associated condition. Elder age was considered as risk factor for cardiovascular disease. Hence it concluded that ARBs are most prescribed drug in monotherapy as it gives clinical as well as statistical significance. In FDCs, most suitable combinations showed significance with Angiotensin Receptor Blockers.

\section{REFERENCES}

1. Appel LJ, JrWright JT, Greene T, Agodoa LY, Astor BC, Bakris GL, et al. Intensive blood-pressure control in hypertensive chronic kidney disease. New England Journal of Medicine. 2010;363(10):918-29.

2. Ghadieh AS, Saab B. Evidence for exercise training in the management of hypertension in adults. Canadian Family Physician. 2015;61(3):233-9.

3. Chockalingam A, Campbell NR, Fodor JG. Worldwide epidemic of hypertension. The Canadian Journal of Cardiology. 2006;22(7):553.

4. Walley T, Duggan AK, Haycox AR, Niziol CJ. Treatment for newly diagnosed hypertension: Patterns of prescribing and antihypertensive effectiveness in the UK. Journal of the Royal Society of Medicine. 2003;96(11):525-31.

5. James PA, Oparil S, Carter BL, Cushman WC, Dennison-Himmelfarb C, Handler $\mathrm{J}$, et al. Evidence-based guideline for the management of high blood pressure in adults: Report from the panel members appointed to the Eighth Joint National Committee (JNC 8). JAMA. 2014;311(5):507-20.

6. Machado MA, DeMoura CS, Wang Y, Danieli C, Abrahamowicz M, Bernatsky $S$, et al. Comparative effectiveness of antihypertensive drugs in nondiabetic patients with hypertension: A population-based study. The Journal of Clinical Hypertension. 2017;19(10):999-1009.

7. Walker R. Clinical Pharmacy and Therapeutics E-Book. Elsevier Health Sciences. 2011.

8. Singh S, Shankar R, Singh GP. Prevalence and associated risk factors of hypertension: A cross-sectional study in urban Varanasi. International Journal of Hypertension. 2017

9. Gress TW, Nieto FJ, Shahar E, Wofford MR, Brancati FL. Hypertension and antihypertensive therapy as risk factors for type 2 diabetes mellitus. New England Journal of Medicine. 2000;342(13):905-12.

10. Chen N, Zhou M, Yang M, Guo J, Zhu C, Yang J, et al. Calcium channel blockers versus other classes of drugs for hypertension. Cochrane Database of Systematic Reviews. 2010(8)

11. Al-Drabah E, Irshaid Y, Yasein N, Zmeili S. Prescription pattern of antihypertensive drugs in Family Practice Clinics at Jordan University Hospital. Med Sci. 2013;2(1):469-88.

12. Israili ZH. Clinical pharmacokinetics of angiotensin II (AT 1) receptor blockers in hypertension. Journal of Human Hypertension. 2000;14(S1):S73.

13. VermaAA, Khuu W, Tadrous M, Gomes T, Mamdani MM. Fixed-dose combination antihypertensive medications, adherence and clinical outcomes: A populationbased retrospective cohort study. PLoS Medicine. 2018;15(6):e1002584. 